\title{
KETONURIA AND URINARY ACIDITY
}

\author{
BY \\ KENNETH H. TALLERMAN, M.C., M.D., M.R.C.P. \\ (From The Hospital for Sick Children, Great Ormond Street.)
}

\section{Introduction.}

The significance of acetone bodies in the urine subsequent to surgical operations has long been the cause of controversy and is not as yet settled.

It is now well recognised that ketone bodies are not necessarily associated with acidosis. Although a ketosis usually accompanies an acidosis, the reverse is by no means the case. Despite the fact that a true acidosisa depletion of the alkali reserve of the blood-is not necessarily indicated by ketonuria, the finding of acetone bodies in the urine following an operation, is still in clinical work frequently looked upon as a matter of much significance, especially in children. The estimation of the alkali reserve of the blood in the presence of an acid urine will, of course, at once decide whether a condition of acidosis be present or not. 'This, however, is rarely a possible procedure in practice and cannot always be undertaken even in a hospital. The clinical symptoms accompanying a definite case of acidosis also make this condition clear, but again, one would wish to have warning before the development of air hunger and collapse. Any information likely to be of assistance from a clinical point of view would be of advantage and any simple means of obtaining this, a help.

The acid-base equilibrium of the body is maintained by the kidneys as well as by the lungs. It is reasonable to suppose, then, that a consideration of urinary acidity would be of much value in dealing with patients exhibiting a ketosis. On this account an investigation has been carried out to determine how far post-operative ketosis, judged by the usual qualitative tests, is related to the acidity of the urine. It seemed probable that a simple method of estimating such acidity by means of indicators would be of value and give a better idea of the patient's condition than could be obtained by merely testing the urine for acetone bodies. The tests employed for this purpose are not only open to criticism (Bigwood and Ladd)(1), but, even in cases where acidosis is present, it has been shown that ketone bodies cannot be held responsible. (2) (3)

Methods.

Although the reaction of the urine varies to a considerable extent from time to time, in the normal condition the range lies between $\mathrm{pH} .7 \cdot 5-5 \cdot 0$. Unless the reaction lies below $\mathrm{pH} .5 \cdot 0$, acidosis can be ruled out.

Brom-cresol-purple covers the usual range better than any other indicator, its range of reaction lying between $\mathrm{pH} .6 \cdot 8-5 \cdot 2$. On this account it is known that an acidosis can be excluded if a urine is alkaline to this indicator. At the same time, however, owing to the difficulty of reading the colours at either end of this range, and to a urine being at times much more acid or alkaline, brom-cresol-purple alone will not suffice in carrying out estimates of urinary $\mathrm{pH}$. 
Methyl red ( $\mathrm{pH}$. 6.0-4.6) was used for readings on the acid side, and phenol red $(\mathrm{pH} .8 \cdot 4-6 \cdot 0)$ for those on the alkaline.

Five cc. of urine were measured into a tube and five drops of the indicator added. This was put in a comparator and read against Clark and Lubs standards made up with a similar mount of indicator. The standards were, of course, backed with tubes containing some of the urine being investigated. The urines were filtered where necessary and tubes of a like calibre used throughout.

The ferric chloride and Rothera's sodium nitroprusside tests were used to determine the presence of acetone bodies. The investigation was carried out upon the urines of children who had undergone tonsillectomy on the previous day and who subsequently developed ketosis. None of them developed abnormal symptoms. Controls were obtained by examining urines of children, mostly convalescent, in whom ketosis was absent.

It is realised that the reaction of the urine varies to some extent throughout the day, owing to the alkaline tide. The conditions under which the urine of post-operative cases and the controls were obtained were, however, comparable.

The patients undergoing the operations, and whose urine was subsequently investigated, were all otherwise healthy, and there is therefore no reason to suppose that there was any renal inefficiency which might prevent the output of acid salts.

TABLE I.

Cases exhibiting Marked Ketosis. $\mathrm{pH}$.

$\mathrm{pH}$.

$\mathrm{pH}$.

1. L.W. $\quad 5^{\circ} 9$

11. A.H. 5.5

21. M.C. 55

2. B.A. $6^{\circ} 0$

12. J.V. $5^{\circ} 4$

22. R.S. 60

3. S.C. 5.7

4. C.S. 6.2

13. D.B. $5^{\circ} 6$

14. V.R. 53

23. A.A. $5^{\circ} 8$

5. H.M. $6^{\circ} 2$

15. D.S. $5^{\circ} 6$

24. R.B. 58

6. J.S. $5^{\circ} 6$

16. E.W. $5^{\circ} 6$

25. J.A. 55

7. W.P. $5{ }^{\circ} 7$

8. L.P. $5 \%$

17. E.T. $5 \cdot 7$

18. P.R. $5{ }^{\circ} 9$

26. E.M. 54

27. M.S. $5{ }^{\circ}$

19. L.P. $5^{\circ} 6$

28. P.S. $5{ }^{\circ} 8$

9. D.A. $5^{\circ} 6$

20. L.S. $6^{\circ} 0$

29. H.A. $6{ }^{\circ} 2$

10. D.S. $5^{\circ} 6$

Average : pH. $5^{\circ} 72$.

30. W.J. 5.8

\section{TABLE II.}

Cases exhibiting Ketosis, but to a less marked degree than the above.

$\begin{array}{lll} & & \text { pH. } \\ \text { 1. } & \text { C.M. } & 6^{\circ} 0 \\ \text { 2. } & \text { L.K. } & 6^{\circ} 0 \\ \text { 3. } & \text { S.W. } & 6^{\circ} 8 \\ \text { 4. } & \text { D.V. } & 6^{\circ} 2\end{array}$

$\begin{array}{lll} & & \mathrm{pH} . \\ \text { 5. } & \text { H.B. } & 6^{\circ} 0 \\ \text { 6. } & \text { M.H. } & 5^{\circ} 6 \\ \text { 7. } & \text { F.D. } & 6^{\circ} 8 \\ \text { 8. } & \text { J.W. } & 6^{\circ} 8\end{array}$

9. R.L. $6^{\circ} 6$

0

Average: pH. $6^{\circ} 21$.

10. J.M. 5.8

11. D.U. $5^{\circ} 7$

12. Y.J. 6.2 
TABLE III.

\begin{tabular}{|c|c|c|c|c|c|c|c|}
\hline \multicolumn{8}{|c|}{ Controls-(Complete absence of Retosis.) } \\
\hline & $\mathrm{pH}$. & & & $\mathrm{pH}$. & & & $\mathrm{pH}$. \\
\hline B.L. & 7.0 & 11. & S.D. & 64 & 21. & H.B. & $6+$ \\
\hline D.R. & $5 \cdot 8$ & 12. & D.M. & $5 \cdot 5$ & 22. & J.W. & 68 \\
\hline A.T. & 64 & 13. & R.B. & $6^{\circ} 0$ & 23. & F.P. & $7^{\circ} 4$ \\
\hline H.B. & 6.4 & 14. & D.W. & 58 & 24. & J.W. & $5 \cdot 2$ \\
\hline G.R. & 5.8 & 15. & J.C. & $6 \%$ & 25. & B.C. & 5.6 \\
\hline M.T. & $7^{\circ} 0$ & 16. & C.F. & 5.8 & 26. & J.W. & 5.5 \\
\hline P.M. & $7 \cdot 2$ & 17. & J.W. & 6.8 & 27. & W.D. & 6.8 \\
\hline A.H. & 6.2 & 18. & M.P. & $6^{\circ} 9$ & 28. & D.B. & 6.8 \\
\hline M.S. & $6 \cdot 2$ & 19. & D.A. & $7^{\circ} 0$ & 29. & M.L. & 6.8 \\
\hline A.S. & 64 & 20. & M.A. & $6 \% 6$ & 30. & A.H. & 6.0 \\
\hline
\end{tabular}

Average: pH. 6.37.

Results and Discussions.

Table I. shows the urinary $\mathrm{pH}$. of 30 cases, all of which exhibited marked ketosis as judged by the usual qualitative tests. The average acidity was $\mathrm{pH} . \mathbf{5 \cdot 7 2}$.

In Table II. is set out the pH. of urines in a series showing definite, but less marked ketosis. The average $\mathrm{pH}$. was $6 \cdot 21$.

Table III. shows the reaction of the control urines in which the average pH. was $6 \cdot 37$.

Henderson and Palmer, who also carried out colorimetric determinations of urinary $\mathrm{pH}$. in 1913, obtained an average of $\mathrm{pH} .6 \cdot 03$ for normal urines. ${ }^{(4)}$

It will be seen that in no instance did the urinary $\mathrm{pH}$. fall below $5 \cdot 3$ in the series given in Table $I$. That is to say, that the reaction lay approximately within normal limits and never approached a point indicative of acidosis.

It will be observed that the urines given in Table II. show hardly any difference in their acidity, though ketosis in them was much less marked.

An average urinary $\mathrm{pH}$. of 6.37 was obtained in the control cases (Table III.). Ten of these 30 , however, had urinary acidities ranging between $\mathrm{pH} .6 \cdot 0-5 \cdot 2$, despite the absence of ketosis. Conversely, it should be noted that of the total number of cases exhibiting ketosis (Tables I. and II.), in 15 the $\mathrm{pH}$. lay between $6 \cdot 0-6 \cdot 8$.

Although on the average the urinary acidity is greater in those cases where ketone bodies were present, the variation from the normal is slight. In no case, moreover, was a urine encountered where the urinary acidity approached a $\mathrm{pH}$. indicative of an acidosis. This despite the fact that the tests for acetone bodies were strongly positive.

Unless a patient is passing at least $1 \mathrm{gm}$. of acetone bodies in the 24 hours the ketosis is unlikely to be serious per se. In the absence of any quantitative estimations the mere qualitative tests may well mean nothing, even if strongly positive.

It may be considered that apart from any question of acidosis, the ketone bodies themselves have a harmful effect. Provided, however, that the patient is devoid of clinical symptoms and the urinary reaction lies on the alkaline side of $\mathrm{pH} .5 \cdot 2$ it seems unreasonable to regard post-operative occurrence of acetone bodies in urine with any anxiety whatever. 
Although the estimations of urinary $\mathrm{pH}$. were carried out for the purposes of this paper as described above, a sufficiently close indication of the acidity can be obtained without any special apparatus, simply by the use of indicators as follows :-

Take an inch of urine in a test tube. Add five drops of brom-cresolpurple $(0.04 \%$ aqueous sol.). If the colour obtained is purplish, no further tests need be carried out. The $\mathrm{pH}$. is on the alkaline side of $6 \cdot 4$.

If a yellow colour is obtained, add to a like quantity of urine in another tube, five drops of methyl red $(0.02 \%$ in $60 \%$ alcoholic sol.). If the colour then obtained is yellowish orange and not a deep pink, the urinary acidity lies to the alkaline side of $\mathrm{pH} .5 \cdot 4$ and no danger from an acidosis need be fearèd.

In the above work it was found that these two indicators were for practical purposes satisfactory for the range with which one is likely to be concerned.

\section{Summary and Conclusions.}

1. Qualitative tests for acetone bodies give but a rough measure of the degree of ketonuria present and should not be regarded as necessarily any evidence of acidosis.

2. The average urinary $\mathrm{pH}$. of 42 cases exhibiting ketosis was $5 \cdot 86$, while that of the controls was $6 \cdot 37$.

3. In none of the above cases of ketosis following tonsillectomy was a urinary acidity encountered which approached a point indicative of acidosis. The $\mathrm{pH}$. lay within normal limits in every case.

4. A simple method of testing the urinary acidity is described. It is felt that this will give more accurate information relative to acidosis than the qualitative tests for acetone bodies in the urine. This is especially the case in view of the great increase of total organic acids in the urine known to occur in an acidosis.

I wish to express my thanks to those members of the staff who allowed me access to patients under their care, and to Dr. (i. A. Harrison for his kindly criticism and advice.

\section{REFERENCES.}

1. Bigwood, L. J., and Ladd, W. S. : Journ. Biol. Chem., 1923, 1xviii., 347.

2. Jeans, P. (., and Johnson, M. : Amer. Journ. Dis. Child., 1917, xiv., 57.

3. Jeans, P. (., and lallerman, K. H.: Brit. Journ. Dis. Child., 1924, xxi., 268.

4. Henderson, I. J., and Palmer, W. W. : Journ. Biol. Chem., 1913, xiii., 393. 